\title{
Hyponatremia in elderly patients with fragility fractures of the proximal femur: a cross-sectional study
}

\author{
Hiponatremia em pacientes idosos com fratura proximal de fêmur \\ por fragilidade: um estudo transversal
}

\section{Authors}

Aída Fernanda Batista Rocha ${ }^{(\mathbb{D}}$ Marcus Villander Barros De Oliveira Sá ${ }^{(\mathbb{1}}$

Ubirace Fernando Elihimas Junior $^{3}{ }^{(D)}$

\footnotetext{
${ }^{1}$ Universidade Federal de Pernambuco, Hospital das Clínicas, Recife, PE, Brasil. ${ }^{2}$ Real Hospital Português, Recife, PE, Brasil.

${ }^{3}$ Real Hospital Português, Unidade de Nefrologia, Recife, PE, Brasil.
}

Submitted on: 01/16/2019. Approved on: 04/24/2019.

\section{Correspondence to:}

Aída Fernanda Batista Rocha E-mail: aida.nandabr@gmail.com

DOI: 10.1590/2175-8239-JBN-2019-0019

\section{Abstract}

Introduction: Proximal femur fractures affect the mortality and morbidity of elderly individuals. Recent studies have shown an association between fragility fractures and hyponatremia, a common fluid and electrolyte balance disorder. Objectives: This study aimed to investigate the occurrence of hyponatremia in patients with fragility fractures of the proximal femur. Methods: The authors looked into the data from the medical records of patients admitted to the emergency unit of the Real Hospital Português for fragility fractures of the proximal femur from 2014 to 2017. The study included patients with serum sodium levels recorded in their charts. Results: Fourteen of $69(20.3 \%)$ patients with proximal femur fractures had hyponatremia. The main factors linked to hyponatremia were lung disease, and prescription of amiodarone and/or antidepressants. Conclusion: In elderly individuals, fragility fractures of the proximal femur may correlate with hyponatremia, particularly among patients on amiodarone or antidepressants.

Keywords: Hyponatremia; Fractures, Bone; Femur; Aged.

\section{INTRODUCTION}

Hyponatremia is the most common fluid and electrolyte balance disorder. ${ }^{1}$ Some authors have described a correlation between hyponatremia and proximal femur fractures. ${ }^{2,3,4}$ Patients with asymptomatic hyponatremia are at higher risk of falling on account of gait disorders. ${ }^{5}$ Additionally, hyponatremia may also stem from decreased bone mineral density secondary to osteoclast activation. ${ }^{2}$ In 2011, Barsoni

\section{Resumo}

Introdução: Fratura de fêmur proximal tem impacto na mortalidade e morbidade de idosos. Estudos recentes vêm demonstrando associação entre fratura por fragilidade e hiponatremia, um distúrbio hidroeletrolítico comum na prática médica. Objetivos: Investigar a ocorrência de hiponatremia em pacientes com fratura proximal de fêmur por fragilidade. Metodologia: Foram coletados dados a partir de prontuários de pacientes admitidos na emergência do Real Hospital Português devido à fratura proximal de fêmur por fragilidade, entre 2014 e 2017, e aqueles com natremia disponível no prontuário eletrônico foram incluídos no estudo. Resultado: Dentre os 69 pacientes com fratura de fêmur proximal, houve uma ocorrência de 14 pacientes com hiponatremia, o que corresponde a $20,3 \%$. Os principais fatores associados à hiponatremia no estudo foram doença pulmonar, uso de amiodarona e antidepressivos. Conclusão: Em idosos, a fratura de fêmur proximal por fragilidade pode estar correlacionada com hiponatremia, principalmente quando estão sob uso de amiodarona ou antidepressivos.

Palavras-chave: Hiponatremia; Fraturas Ósseas; Fêmur; Idoso. et al. submitted that hyponatremia might induce oxidative stress on osteoclasts, in a proposition known as the theory of oxidative stress on ascorbic acid transporters. ${ }^{6}$ In 2016, Fibbi et al. described hyponatremia as a regulator of the expression of genes MCP-1 (Monocyte chemoattractant protein-1) and CXCL-12 (C-X-C Motif Chemokine Ligand 12) connected to osteoclastogenesis - the osteoclastogenesis modulation theory. ${ }^{\text {? }}$ 
The etiology of hyponatremia must be defined before specific medical treatment is prescribed. $^{8}$ Hyponatremia may be categorized based on the volume status of the patient as hypovolemic, euvolemic, or hypervolemic. ${ }^{9}$ Syndrome of inappropriate secretion of antidiuretic hormone (SIADH) ranks as one of the main causes of euvolemic hyponatremia. ${ }^{8}$ SIADH may occur secondarily to malignant lung, mediastinal, gastrointestinal, and genitourinary tumors. SIADH may originate from asthma, cystic fibrosis, chronic obstructive pulmonary disease (COPD), and infectious lung diseases such as viral or bacterial pneumonias, tuberculosis, aspergillosis, and lung abscesses. SIADH may be caused by other neurologic factors including vascular malformations, mass lesions, stroke, head trauma, and infections such as encephalitis, meningitis, malaria, acquired immunodeficiency syndrome, and brain abscesses. SIADH may still occur in association with the use of medications such as vasopressin analogues, antidepressants, antipsychotics, anticonvulsants, cancer drugs, opioids, proton pump inhibitors, amiodarone, and non-steroid anti-inflammatory drugs. ${ }^{10}$

Falling is a common incident among the elderly that impacts their morbidity and mortality. An estimated $30 \%$ of the individuals aged $65+$ years fall every year (Yale Health Project 1988), ${ }^{11}$ an event responsible for approximately $5 \%$ of the hospitalizations of elderly persons. ${ }^{12}$ Hip fractures are placed among the most severe consequences of falling, with reported one-year mortality ranging between $26 \%$ and $33 \% .^{13}$ Several instruments have been developed to identify individuals at risk of fracture, such as the Fracture Risk Assessment Tool (FRAX) of the World Heath Organization published in 2008, ${ }^{14}$ and the QFracture algorithm developed for the British population. Since fractures significantly affect the quality of life of elderly individuals and impose a sizable financial burden on healthcare systems, it is only fitting to recognize, prevent, and address risk factors such as hyponatremia. This study aimed to investigate the occurrence of hyponatremia in patients with fragility fractures of the proximal femur.

\section{Methods}

This cross-sectional study was carried out at a tertiary referral hospital in the Brazilian city of Recife to investigate the occurrence of hyponatremia in patients with proximal femur fractures.
The study enrolled elderly patients (individuals with ages $\geq 60$ years, as per the definition of the Brazilian Ministry of Health) $)^{15}$ hospitalized for proximal femur fractures (femoral neck, transtrochanteric, or subtrochanteric fractures $)^{16}$ caused by falls from standing height or less that would not result in fractured bones in the majority of healthy individuals (fragility or low energy fractures). ${ }^{14}$ Additionally, included patients were required to have serum sodium levels recorded in their charts at the time of admission to the emergency unit or at some point in the three months preceding hospitalization.

The patients were analyzed based on the following data: age; sex; serum sodium levels (mild hyponatre$\mathrm{mia}<135 \mathrm{mmol} / \mathrm{L} ;$ moderate hyponatremia $<130$ $\mathrm{mmol} / \mathrm{L}$; or severe hyponatremia $<125 \mathrm{mmol} / \mathrm{L}) ;^{17}$ prescribed medication (amiodarone, benzodiazepines, antidepressants, anticonvulsants, antipsychotics, diuretics, proton pump inhibitors); and comorbidities (systemic hypertension, diabetes mellitus, lung disease, hypothyroidism, heart failure, osteoporosis, history of stroke, dementia, history of bone fracture).

The authors examined the data collected from the charts of patients seen at the emergency unit of the Real Hospital Português from January 1, 2014 to December 31, 2017. The subjects included in the study were divided into two groups based on their serum sodium levels. Group 1 featured patients with hyponatremia (serum sodium $<135 \mathrm{mmol} / \mathrm{L}$ ), while Group 2 enrolled individuals without hyponatremia (serum sodium $\geq 135 \mathrm{mmol} / \mathrm{L}$ ). Statistical analyses were performed on software package R-project 3.4.2. Bartlett's test was used to test the homogeneity of variances. Distribution normality was assessed via the Shapiro-Wilk test. Categorical variables were expressed as frequencies and proportions. Fisher's exact test was used to evaluate the association between categorical variables and hyponatremia, and p-values < 0.05 were deemed significant. Numerical variables were expressed as mean values \pm standard error (SE). Statistical differences between the groups with and without hyponatremia were analyzed with the aid of the Mann-Whitney U test and significance was attributed to differences with a $p$-value $<0.05$.

The Research Ethics Committee of the University of Pernambuco approved this study and assigned it permit CAE 94620518.7.0000.5207 on November 6, 2018. 


\section{Results}

A total of 212 patients were admitted to the emergency unit of the Real Hospital Português from January 1, 2014 to December 31, 2017 for proximal femur fractures. Forty-two were excluded for having ages of less than 60 years. Two patients with bone fractures for being hit by automobiles were also excluded. Ninety-nine were excluded for not having their serum sodium levels measured at admission or in the three months preceding hospitalization for a fractured femur. Therefore, the study population added up to 69 patients (Figure 1).
Nearly four fifths $(79.7 \%)$ of the 69 included patients did not have hyponatremia. In the group with hyponatremia $(20.3 \%)$, mild, moderate, and severe hyponatremia was seen in $78.6 \%, 14.3 \%$, and $7.1 \%$ of the patients, respectively.

Table 1 shows that there was no statistically significant difference in the sex $(p=0.527)$ of age $(p=$ $0.317)$ distributions of the two groups.

The mean serum sodium level seen in Group 1 was statistically different from the level

Table 2 lists the comorbidities observed in the two groups of patients and shows that the individuals in Group 1 had lower serum sodium levels and

Figure 1. Patient selection flowchart

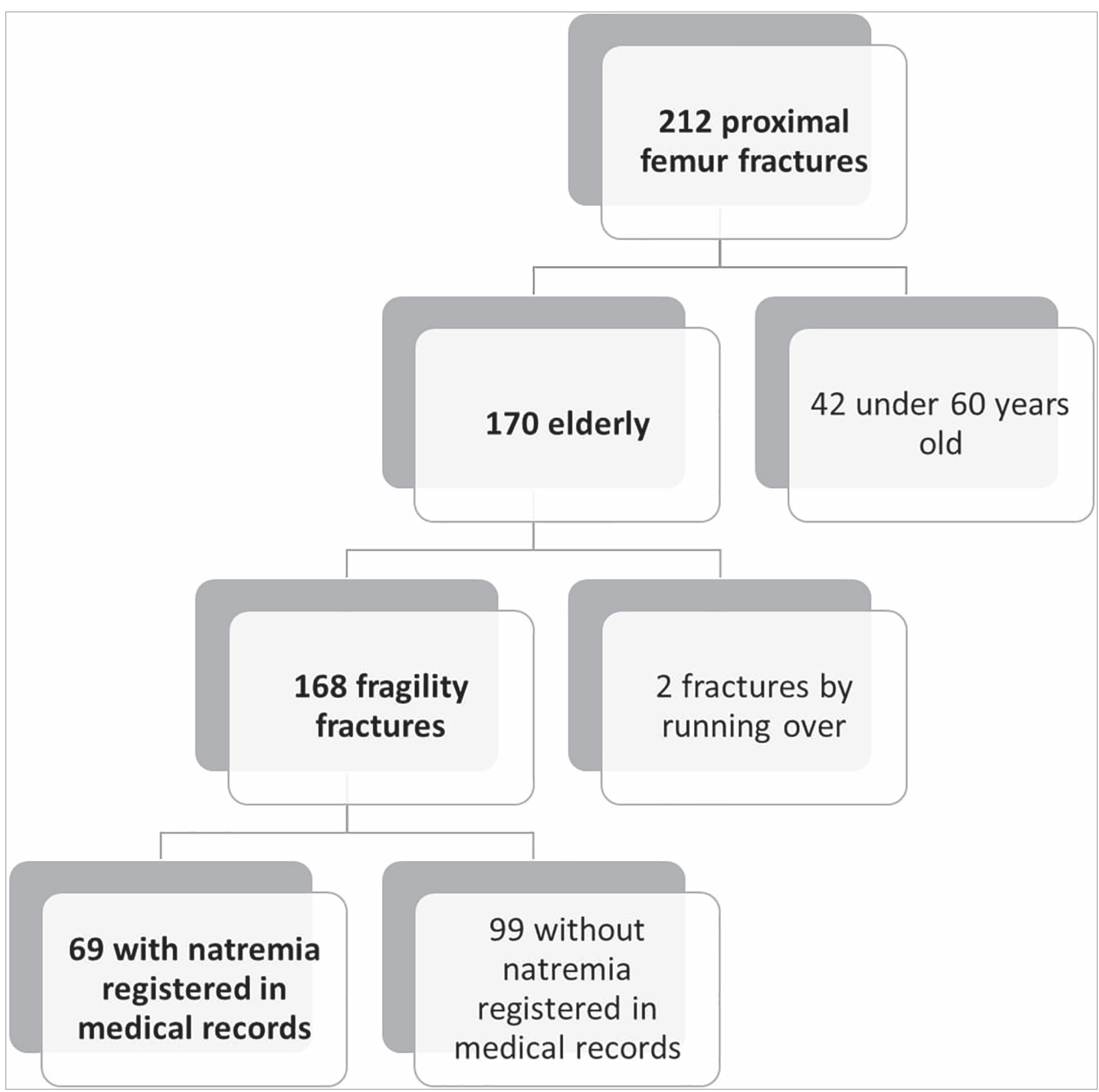




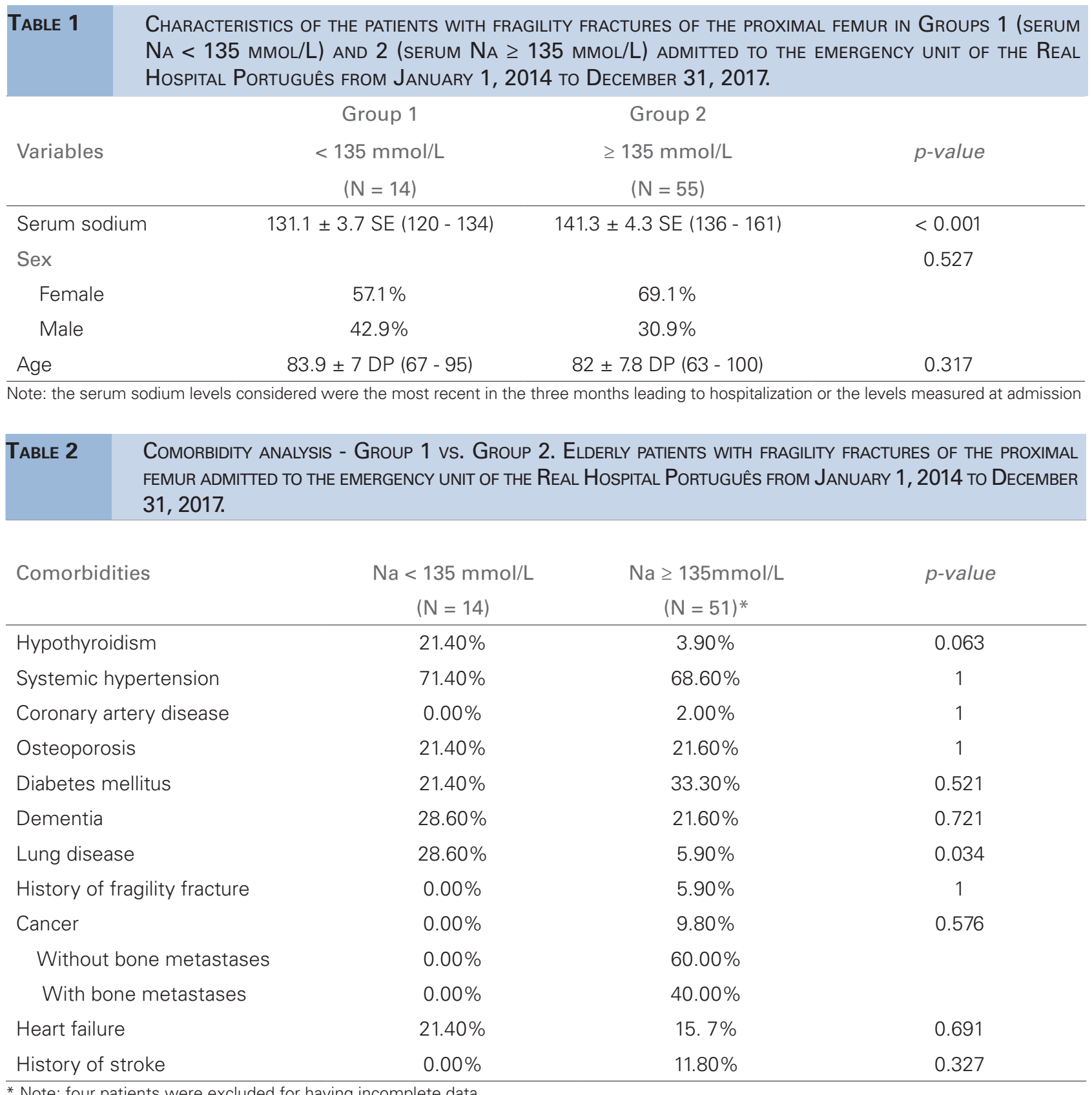

* Note: four patients were excluded for having incomplete data.

significantly greater involvement by lung disease $(p=$ 0.034). Three quarters of the patients with lung disease in Group 1 had COPD and one quarter was diagnosed with idiopathic pulmonary fibrosis. A third of the patients with lung disease in Group 2 had asthma, a third had COPD, and a third was diagnosed with bronchiectasis.

Statistical analysis indicated the existence of a correlation between hyponatremia and amiodarone $(p=0.007)$ and hyponatremia and prescription of antidepressants $(p=0.042)$, as seen in Table 3. The patients included in the study were on the following antidepressants: escitalopram $(25.00 \%)$, mirtazapine
(20.83\%), sertraline $(12.50 \%)$, desvenlafaxine $(8.33 \%)$, trazodone $(8.33 \%)$, duloxetine $(8.33 \%)$, fluoxetine $(4.17 \%)$, paroxetine $(4.17 \%)$, fluvoxamine $(4.17 \%)$, citalopram $(4.17 \%)$, and venlafaxine $(4.17 \%)$, as seen in Figure 2.

\section{Discussion}

This study aimed to investigate the occurrence of hyponatremia in patients with proximal femur fractures. Similarly to prior studies, ${ }^{2-4,18-22}$ fourteen $(20.3 \%)$ of the 69 patients with proximal femur fractures had hyponatremia. The main findings associated with 


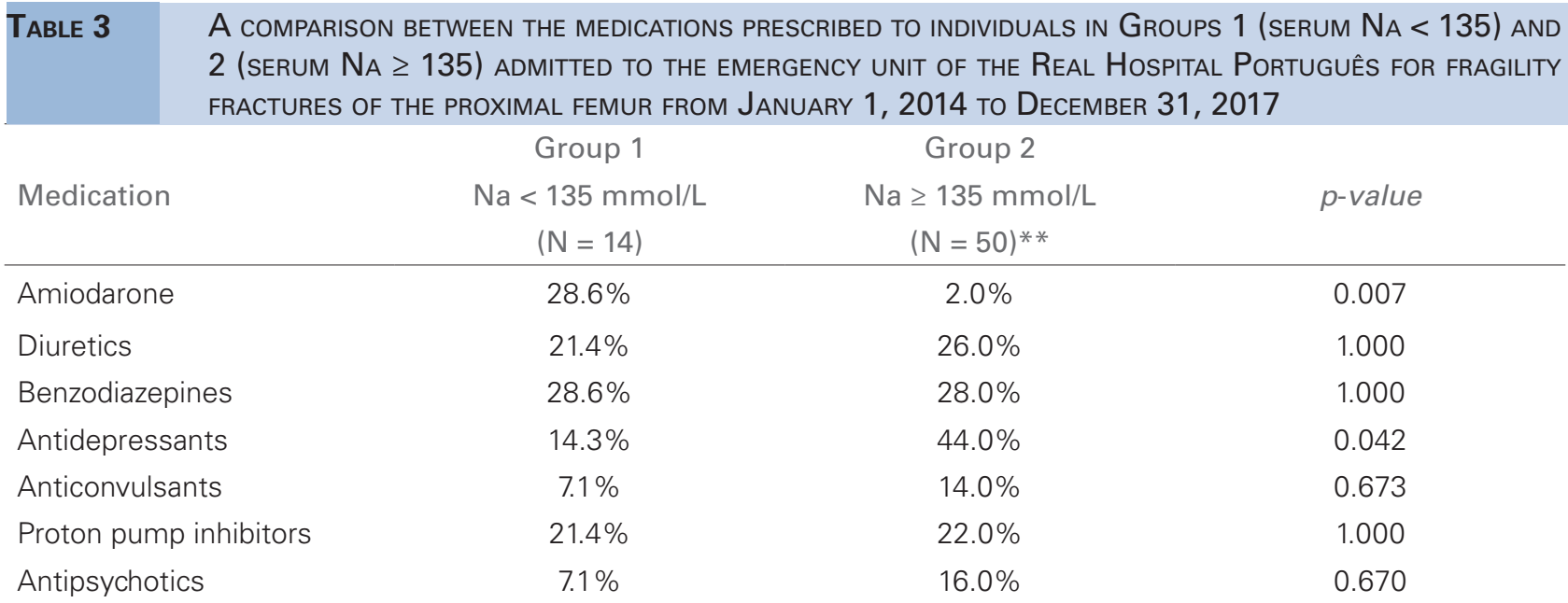

* Note: five patients were excluded for having incomplete data.

Figure 2. Number of patients in each of the prescribed antidepressants.

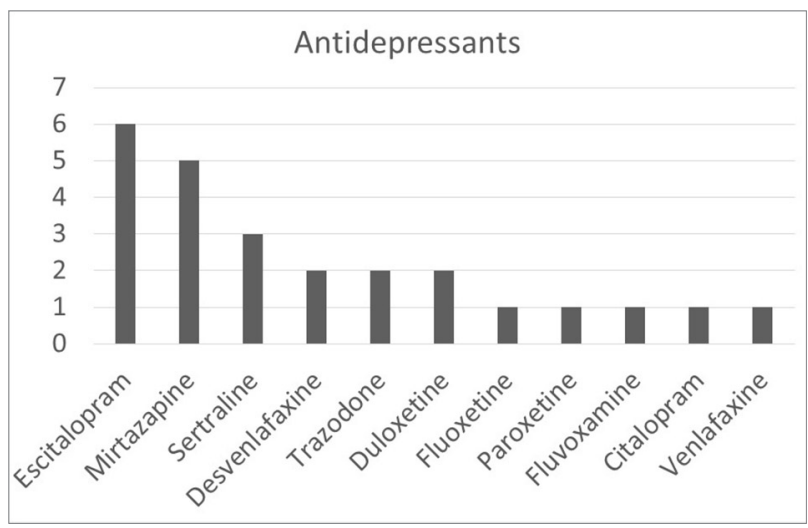

hyponatremia were lung disease and prescription of amiodarone and/or antidepressants.

Hyponatremia may be categorized based on the duration of the disorder as acute ( $<48$ hours) or chronic (> 48 hours). ${ }^{23}$ In chronic hyponatremia, the brain adjusts to the hypotonic environment and clinical manifestations are not quite as exuberant. ${ }^{17}$ Patients with chronic hyponatremia are generally asymptomatic or present with mild clinical anomalies such as attention deficit, gait disorders, falls, and impaired recovery from bone fractures. ${ }^{24,25}$

Upala and Sanguankeo published a meta-analysis featuring 12 trials and observed the existence of a significant association between bone fractures and osteoporosis in individuals with hyponatremia, with an odds ratio (OR) for fracture of 1.99 [95\% confidence interval $(\mathrm{CI}) ; 1.50-2.63 ; p<0.001]$ in studies reporting odds ratios, and increased relative risk (RR) of fracture of $1.62(95 \% \mathrm{CI} ; 1.28-2.05 ; p<0.001)$ in studies reporting risk measurements. ${ }^{2}$
Ayus et al. analyzed a retrospective cohort of 31,527 patients $-0.9 \%$ diagnosed with chronic hyponatremia - and found that the absolute risk of having a hip fracture was $3.07 \%$ in patients with chronic hyponatremia and $1.31 \%$ in individuals with normal serum sodium levels. Patients with hyponatremia had increased adjusted RR of having a hip fracture [4.52 (95\% CI 2.14-9.6)]. The adjusted RR seen for the subset of patients with moderate hyponatremia $<130$ $\mathrm{mmol} / \mathrm{L})$ was even higher [7.61 (95\% CI 2.8-20.5)]. ${ }^{3}$

Gankam Kengne et al. looked into the prevalence of hyponatremia (serum sodium $<135 \mathrm{mmol} / \mathrm{L}$ ) of 513 elderly patients with bone fractures and compared them against controls without fractures matched for sex and age. The prevalence of hyponatremia was significantly higher among individuals with bone fractures than controls (13\% vs. $3.9 \%)$, with an adjusted OR of 4.16 (95\%CI $2.24-7.71)$. In the cited study, hyponatremia was primarily caused by medication - diuretics $(36 \%)$ and selective serotonin re-uptake inhibitors $(17 \%)$ - and SIADH $(37 \%) .{ }^{18}$

In a similar study, Sandhu et al. compared the incidence of hyponatremia in 364 elderly patients admitted to an emergency unit for bone fractures (hip/ pelvis/femur) against another group of 364 elderly patients without bone fractures admitted to the same service within the same time period. The incidence of hyponatremia was significantly higher in the group with bone fractures $(9.1 \%$ vs. $4.1 \%)$. The mean serum sodium level of the individuals in the fracture group was $131 \pm 2$ $\mathrm{mEq} / \mathrm{L}$. More than three quarters $(75.3 \%)$ of the individuals in the bone fracture group were females. Nearly a quarter $(24.2 \%)$ of the patients with bone fractures and 
hyponatremia were on antidepressants, $75 \%$ of which were selective serotonin re-uptake inhibitors (SSRIs). None of the patients in the fracture-free group was on antidepressants. ${ }^{19}$

Jamal et al. reviewed the data from the Osteoporotic Fractures in Men (MrOS) trial to elicit possible relationships between hyponatremia and bone fractures in 5,122 males aged 65 and older. The relative risk for hip fracture was 3.48 (95\% CI: 1.76-6.87). ${ }^{20}$ Kinsella et al. looked into the data from 1,408 females submitted to bone densitometry and found that $18 \%$ had bone fractures. The incidence of hyponatremia was greater in the group with fractures $(8.7 \%)$ than in the fracture-free group $(3.2 \%) .{ }^{21}$

Rittenhouse et al. investigated 2,370 cases of trauma involving elderly individuals and found a prevalence of hyponatremia of $12.4 \%$ (OR: $1.81 ; 95 \% \mathrm{CI}$ : $1.26-2.60 ; p=0.001) .{ }^{22}$ Aicale et al. reported a prevalence of hyponatremia of $19 \%$ in a population of 334 elderly individuals with hip fractures. ${ }^{4}$

Amiodarone-induced hyponatremia is a rare complication, with only 17 cases described in the literature. ${ }^{26}$ The first case report was published in $1996 .{ }^{27}$ The mechanism by which amiodarone induces SIADH is still unclear. ${ }^{28}$ Iovino et al. suggested that amiodarone causes SIADH by stimulating anti-diuretic hormone secretion by the magnocellular neurons in the supraoptic and paraventricular nuclei of the hypothalamus or through the expression of water channel aquaporin-2 (AQP2) in the collecting ducts. ${ }^{29}$

More than a quarter $(28.6 \%)$ of the individuals with hyponatremia included in our study were on amiodarone, suggesting that SIADH secondary to amiodarone prescription might not be that rare.

Prescription of antidepressants has been associated with increased risk of falling and fracture. ${ }^{30}$ Tricyclic antidepressants and mirtazapine have been linked to increased risk of falling on account of their effects in the ability to concentrate and balance, orthostatic hypotension, and sedative effects. ${ }^{31}$ SSRIs reportedly cause dizziness and increase the risk of fractures by decreasing bone mineral density. ${ }^{32}$

Macri et al. showed that subjects on antidepressants were at increased risk of falling when compared to individuals off antidepressants [5.2\% vs. $2.8 \%$; adjusted OR: 1.9, (95\%CI: 1.7-2.2). The authors did not find statistically significant differences between antidepressant classes SSRIs, serotonin and norepinephrine reuptake inhibitors (SNRIs) and trazodone. ${ }^{33}$
Antidepressants increase the risk of falling via several different mechanisms, ${ }^{30}$ and have been considered to cause SIADH. ${ }^{17}$ The results of our study seem to indicate the existence of an association between antidepressants and proximal femur fractures $(p=$ $0.042)$. However, we found more patients on antidepressants in the group with bone fractures without hyponatremia (44\% of the subjects in Group 2 were on antidepressants vs. $14.3 \%$ in Group 1). A third $(33.33 \%)$ of the 69 patients included in our study were on antidepressants. More than half $(54.71 \%)$ of the patients included in our study were on SSRIs; $20.83 \%$ were on SNRIs; $20.83 \%$ were on mirtazapine; and $8.33 \%$ were on trazodone.

There seems to exist a relationship between hyponatremia and fragility fractures of the proximal femur in elderly patients, although recent studies ${ }^{2-4}$ have published new information connecting hyponatremia to falls ${ }^{5}$ and bone fractures. ${ }^{6}$ Serum sodium levels have been underreported for elderly patients admitted for falls. In the study period, only 69 of the 168 elderly individuals admitted for proximal femur fractures had serum sodium levels recorded in their charts - and a meager 45 had serum sodium levels measured upon admission.

Our study showed that amiodarone might be linked to hyponatremia. However, this inference can only be verified through a prospective study designed to establish a causal link between amiodarone and hyponatremia.

Lung diseases such as COPD and asthma or infectious conditions such as tuberculosis, aspergillosis, and bacterial pneumonia have been described as possible causes of SIADH. ${ }^{34}$ Some authors have described hyponatremia in COPD exacerbation. ${ }^{35,36}$ Although the mechanism by which hyponatremia occurs in COPD has not been fully elucidated, it has been suggested that hypercapnia decreases renal blood flow, thereby increasing the retention of water and sodium and causing edema and hyponatremia. ${ }^{37}$

Our study found a significant correlation between hyponatremia and lung disease. The lung diseases for which our patients were tested were COPD, asthma, idiopathic pulmonary fibrosis, and bronchiectasis. Few studies have described a relationship between COPD or asthma and hyponatremia. Further studies enrolling larger populations are required to verify the existence of an association between hyponatremia and the lung diseases analyzed herein. 
SIADH secondary to amiodarone might be underdiagnosed in emergency and trauma centers. We believe that elderly patients on amiodarone or antidepressants should have serum sodium levels measured not only upon admission, but also during regular visits with their physicians. Additional attention is required in the presence of the following triads of findings: falls in the elderly/hyponatremia/amiodarone and falls in the elderly/hyponatremia/antidepressants. When these triads are present, physicians or medical teams with expert knowledge on the matter should further investigate patients for SIADH.

Our study had its share of limitations. The cross-sectional nature of the study and the relative lack of data - only 69 of 168 elderly patients with fragility fractures were included - decreased the sample space. Additionally, the study was carried out in only one regional private tertiary referral hospital.

More studies are needed to assess a possible correlation and the causal links between fragility fractures of the proximal femur and hyponatremia in elderly individuals. Our study found associations between some comorbidities and prescribed medication. Significant associations were found with amiodarone and antidepressants (SSRIs, SNRIs, mirtazapine, and trazodone). In the realm of comorbidities, lung diseases in general (asthma, COPD, idiopathic pulmonary fibrosis, and bronchiectasis) had a relevant role.

\section{AUTHOR'S CONTRIBUTION}

Aída Fernanda Batista Rocha, Marcus Villander Barros De Oliveira Sá, Ubirace Fernando Elihimas Junior contributed substantially to the conception or design of the study; collection, analysis, or interpretation of data; writing or critical review of the manuscript; and final approval of the version to be published.

\section{CONFLict OF INTEREST}

The authors declare that they have no conflict of interest related to the publication of this manuscript.

\section{References}

1. Upadhyay A, Jaber BL, Madias NE. Epidemiology of hyponatremia. Semin Nephrol 2009;29:227-38.

2. Upala S, Sanguankeo A. Association Between Hyponatremia, Osteoporosis, and Fracture: A Systematic Review and Metaanalysis. J Clin Endocrinol Metab 2016;101:1880-6.

3. Ayus JC, Fuentes NA, Negri AL, Moritz ML, Giunta DH, Kalantar-Zadeh K, et al. Mild prolonged chronic hyponatremia and risk of hip fracture in the elderly. Nephrol Dial Transplan 2016;31:1662-9.
4. Aicale R, Tarantino D, Maffulli N. Prevalence of Hyponatremia in Elderly Patients with Hip Fractures: A Two-Year Study. Med Princ Pract 2017;26:451-5.

5. Grundmann F. Electrolyte disturbances in geriatric patients with focus on hyponatremia. Z Gerontol Geriatr 2016;49:477-82.

6. Barsony J, Sugimura Y, Verbalis JG. Osteoclast response to low extracellular sodium and the mechanism of hyponatremiainduced bone loss. J Biol Chem 2011;286:10864-75.

7. Fibbi B, Benvenuti S, Giuliani C, Deledda C, Luciani P, Monici $\mathrm{M}$, et al. Low extracellular sodium promotes adipogenic commitment of human mesenchymal stromal cells: a novel mechanism for chronic hyponatremia-induced bone loss. Endocrine 2016;52:73-85.

8. Janicic N, Verbalis JG. Evaluation and management of hypoosmolality in hospitalized patients. Endocrinol Metab Clin North Am 2003;32:459-81.

9. Adrogué HJ, Madias NE. Hyponatremia. N Engl J Med 2000;342:1581-9.

10. Martins HS, Hernandes PRB, Santos RA. Hiponatremia. In: Martins HS, Brandão Neto RA, Velasco IT. Medicina de Emergência - Abordagem Prática. 12a ed. Barueri: Manole; 2017. p. 1330-49.

11. Tinetti ME, Speechley M, Ginter SF. Risk factors for falls among elderly persons living in the community. $\mathrm{N}$ Engl J Med 1988;319:1701-7.

12. Alexander BH, Rivara FP, Wolf ME. The cost and frequency of hospitalization for fall-related injuries in older adults. Am J Public Health 1992;82:1020-3.

13. Sanz-Reig J, Salvador Marín J, Ferrández Martínez J, Orozco Beltrán D, Martínez López JF, Quesada Rico JA. Prognostic factors and predictive model for in-hospital mortality following hip fractures in the elderly. Chin J Traumatol 2018;21:163-9.

14. Viswanathan M, Reddy S, Berkman N, Cullen K, Middleton JC, Nicholson WK, et al. Screening to Prevent Osteoporotic Fractures: An Evidence Review for the U.S. Preventive Services Task Force. Rockville: Agency for Healthcare Research and Quality/ U.S. Department of Health and Human Services; 2017. Available from: https://www.uspreventiveservicestaskforce.org/ Home/GetFileByID/3427

15. Brazil. Ministério da Saúde. Atenção à Saúde da Pessoa Idosa e Envelhecimento. Brasília: Ministério da Saúde; 2010.

16. Daniachi D, Netto AS, Ono NK, Guimarães RP, Polesello GC, Honda EK. Epidemiologia das fraturas do terço proximal do fêmur em pacientes idosos. Rev Bras Ortop 2015;50:371-7.

17. Spasovski G, Vanholder R, Allolio B, Annane D, Ball S, Bichet D, et al.; Hyponatraemia Guideline Development Group. Clinical practice guideline on diagnosis and treatment of hyponatraemia. Nephrol Dial Transplant 2014;29:1-39.

18. Gankam Kengne F, Andres C, Sattar L, Melot C, Decaux G. Mild hyponatremia and risk of fracture in the ambulatory elderly. QJM 2008;101:583-8.

19. Sandhu HS, Gilles E, DeVita MV, Panagopoulos G, Michelis MF. Hyponatremia associated with large-bone fracture in elderly patients. Int Urol Nephrol 2009;41:733-7.

20. Jamal SA, Arampatzis S, Harrison SL, Bucur RC, Ensrud K, Orwoll ES, et al. Hyponatremia and fractures: Findings from the MrOS study. J Bone Miner Res 2015;30:970-5.

21. Kinsella S, Moran S, Sullivan MO, Molloy MG, Eustace JA. Hyponatremia independent of osteoporosis is associated with fracture occurrence. Clin J Am Soc Nephrol 2010;5:275-80.

22. Rittenhouse KJ, To T, Rogers A, Wu D, Horst M, Edavettal $\mathrm{M}$, et al. Hyponatremia as a fall predictor in a geriatric trauma population. Injury 2015;46:119-23.

23. Kumar S, Berl T. Sodium. Lancet 1998;352:220-8.

24. Renneboog B, Musch W, Vandemergel X, Manto MU, Decaux G. Mild chronic hyponatremia is associated with falls, unsteadiness, and attention deficits. Am J Med 2006;119:71.e1-8.

25. Hoorn EJ, Rivadeneira F, van Meurs JB, Ziere G, Stricker $\mathrm{BH}$, Hofman A, et al. Mild hyponatremia as a risk factor for fractures: The Rotterdam Study. J Bone Miner Res 2011;26:1822-8. 
26. Barham W, Zeayter SA, Safadi A, Thakur RK. Amiodaroneinduced Hyponatremia: A Case Report and a Review of the Literature. J Innov Card Rhythm Manag 2018;9:3071-6.

27. Nakamura M, Sunagawa O, Kugai T, Kinugawa K. Amiodarone-Induced Hyponatremia Masked by Tolvaptan in a Patient with an Implantable Left Ventricular Assist Device. Int Heart J 2017;58:1004-7.

28. Dutta P, Parthan G, Aggarwal A, Kumar S, Kakkar N, Bhansali A, et al. Amiodarone Induced Hyponatremia Masquerading as Syndrome of Inappropriate Antidiuretic Hormone Secretion by Anaplastic Carcinoma of Prostate. Case Rep Urol 2014;2014:136984.

29. Iovino M, Iovine N, Petrosino A, Licchelli B, Giagulli V, Iacoviello $\mathrm{M}$, et al. Amiodarone-induced SIADH: two cases report. Endocr Metab Immune Disord Drug Targets 2014;14:123-5.

30. Marcum ZA, Perera S, Thorpe JM, Switzer GE, Castle NG, Strotmeyer ES, et al.; Health ABC Study. Antidepressant Use and Recurrent Falls in Community-Dwelling Older Adults: Findings From the Health ABC Study. Ann Pharmacother 2016;50:525-33.

31. American Geriatrics Society 2015 Beers Criteria Update Expert Panel. American Geriatrics Society 2015 Updated Beers Criteria for Potentially Inappropriate Medication Use in Older Adults. J Am Geriatr Soc 2015;63:2227-46.
32. Coupland C, Hill T, Morriss R, Moore M, Arthur A, HippisleyCox J. Antidepressant use and risk of cardiovascular outcomes in people aged 20 to 64 : cohort study using primary care database. BMJ 2016;352:i1350.

33. Macri JC, Iaboni A, Kirkham JG, Maxwell C, Gill SS, Vasudev A, et al. Association between Antidepressants and Fall-Related Injuries among Long-Term Care Residents. Am J Geriatr Psychiatry 2017;25:1326-36.

34. Henry DA. In The Clinic: Hyponatremia. Ann Intern Med 2015;163:ITC1-19.

35. Goli G, Mukka R, Sairi S. Study of serum electrolytes in acute exacerbation of chronic obstructive pulmonary disease patients. Int J Res Med Sci 2016;4:3324-7.

36. Winther JA, Brynildsen J, Høiseth AD, Følling I, Brekke PH, Christensen G, et al. Prevalence and Prognostic Significance of Hyponatremia in Patients with Acute Exacerbation of Chronic Obstructive Pulmonary Disease: Data from the Akershus Cardiac Examination (ACE) 2 Study. PLoS One 2016;11:e0161232.

37. Valli G, Fedeli A, Antonucci R, Paoletti P, Palange P. Water and sodium imbalance in COPD patients. Monaldi Arch Chest Dis 2004;61:112-6. 